的 the stability and collapse of sand piles, and the forensic study of sand to solve murders. This leads to a discussion of the weird and wonderful microscopic life forms - such as rotifers, tardigrades, gastrotrichs, turbellarians and others - that have evolved to flourish in the spaces between shifting, abrasive sand grains. Such an environment may become the last refuge for life in the event of catastrophic climate

change. Welland then addresses sand on a progressively larger scale: along the course of meandering rivers, in the formation of beaches, in deserts and mid-ocean sandbanks, in the formation of Old Red Sandstone rocks found extensively from the Arctic to the Gulf of Mexico and, finally, in sand found beyond Earth.

Welland asks how sand grains have helped humans to conceive the Universe and the infinite. He begins with Archimedes who, in the third century $\mathrm{BC}$, calculated that $10^{63}$ grains of sand would fill the Universe to the outermost sphere of the fixed stars. The author also discusses, and attractively illustrates, how sand has been used artistically in many cultures - from sand painting by Australian aboriginal communities and the North American Navajo, to Zen sand gardens in Japan and the sand sculptures created by digital methods at the Media Lab at the Massachusetts Institute

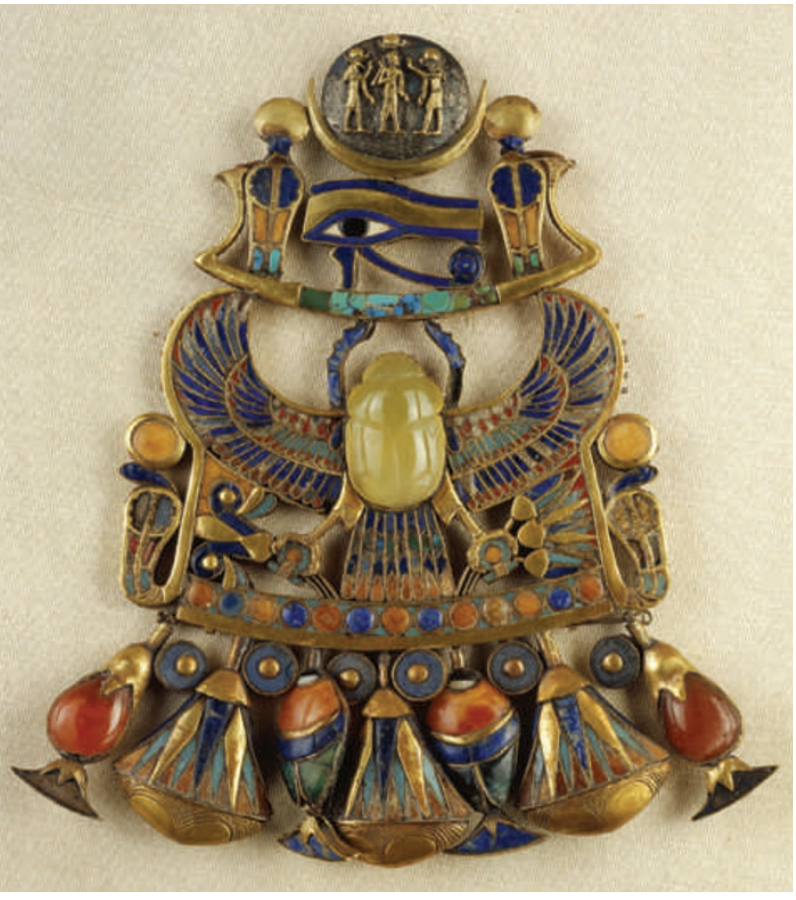

Green desert glass from Libya was carved into a scarab beetle for Tutankhamun's necklace - but how did the silica glass form?

of Technology in Cambridge. One fascinating photograph shows the 'Earthquake Rose', the pattern made by a desktop toy, a sand-tracing pendulum, during a strong earthquake in Washington state in 2001.

A personal epilogue provides the reader with a genuine mystery. In 1922, the discovery of Tutankhamun's tomb in Egypt yielded a famous necklace with a scarab beetle carved from a glowing, yellow-green, gem-like material, which its discoverer Howard Carter did not recognize. In the 1990s, the material was shown to be a unique silica glass, 28 million years old and $98 \%$ pure, from a particular part of the Libyan desert.

Welland travels to this desolate spot and cherishes the glassy samples he finds glittering on the dunes. But, he muses, what could have produced heat that was intense enough to fuse silica? A strike from a meteorite or lightning can be ruled out because of the lack of visible impact craters or hollow fulgurite tubes, respectively. He speculates that the cause might have been an air burst from the impact of an asteroid with the atmosphere, similar to that at Tunguska in Siberia, Russia, in 1908 .

With irresistible ideas such as this, Welland provides an appealing blend of science and the imagination, worthy of the famous vision of the poet William Blake: "To see a world in a grain of sand".

Andrew Robinson is the author of Earthshock and The Story of Measurement. He is a visiting fellow of Wolfson College, Cambridge CB3 9BB, UK. e-mail: ar471@cam.ac.uk

\title{
D-Day forecast fictionalized
}

\section{Turbulence by Giles Foden \\ Faber and Faber: 2009. 368 pp. £16.99}

Fluid dynamics and weather prediction seem unpromising material for a gripping story. But Giles Foden has ingeniously dramatized what is perhaps the most important weather forecast ever made: that for the D-Day landings, the invasion of continental Europe at Normandy by the Allied forces towards the end of the Second World War. The result is a compelling tale, with meteorologists as the unlikely heroes and the turbulence of the title providing the central metaphor.

General Dwight D. Eisenhower, in command of the operation, had to be sure that the crossing of the English Channel would not be disrupted by bad weather. And he needed that assurance five days in advance - a length of time that stretches today's forecasting techniques to their limit, and which was beyond the capability of meteorologists in 1944. Add to that the need for a low tide to evade the German sea defences, the task confronting the Allies' weather experts seemed insurmountable.

In Turbulence, Foden tells this story through the eyes of a fictional character, Henry Meadows, a young academic attached to the forecasting team that is led, as it was in reality, by the British meteorologist James Stagg. The decision-making process of Stagg and his fractious colleagues, including the brash American entrepreneur Irving Krick and the arrogant but astute Norwegian Sverre Petterssen, occupies the last third of the book. Stagg and Petterssen each published their own accounts in the 1970s. Although Foden's tale is steeped in that history, he allows Meadows to make the crucial, unrecognized contribution.
The story begins with Meadows being sent to rural Scotland to glean clues about forecasting from the leading authority of the day, the difficult genius Wallace Ryman. Ryman is a fictionalized version of Lewis Fry Richardson, known for his work on fractal coastlines, who Foden rightly calls "one of the unsung heroes of British science". Like Richardson, Ryman is a Quaker whose experiences in the Friends' Ambulance Unit during the First World War convinced him that war must be avoided. He shuns collaboration with the military, so Meadows must pursue his mission by stealth - an attempt that he mostly bungles.

In Scotland, Meadows runs into the second wayward genius in the book, this time without a pseudonymous disguise: Geoffrey Pyke, the man behind the Habbakuk project to build aircraft carriers out of ice reinforced with wood pulp. This 'Pykrete' is extraordinarily resistant to impacts and melting. Also making a fleeting appearance is Julius Brecher, a doppelgänger for biochemist Max Perutz, who assisted Pyke during the war. This part of the plot would seem far-fetched if you didn't know that it is true. 
Yet the Habbakuk story, however entertaining, seems tacked on. It is not central to the plot even though it supplies a framing device: Meadows recounts his wartime exploits while on board an ice ship built in 1980 for an Arab sheikh. When Meadows joins Pyke in wartime London only to see the Habbakuk project terminated, it feels like a cul-de-sac. One could carp at a few other points of creaky plotting or narrative, but that seems churlish given how splendidly the book animates a buried story of scientific endeavour and triumph.

One must also ask whether the author succeeds in creating scientists who are fully fleshed individuals. Foden complicates his task by making Meadows callow and withdrawn as a result of a childhood trauma in Africa.

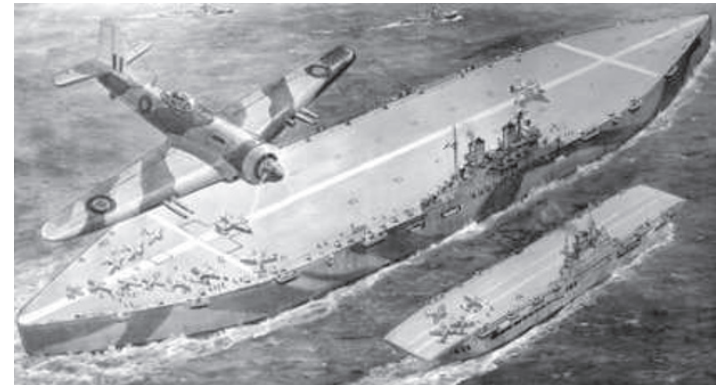

Secret wartime plans included building giant ships from ice.

Meadows's fixation on his research and his social awkwardness could make him a caricature of the diffident scientist. Brecher also refracts everything through the prism of his own research topic of blood, while Ryman is the crabby boffin and Pyke the dotty one.
But Foden has a motive in shaping Meadows this way, using him to capture a sense of the dour, buttoned-up character of wartime Britain. And unlike so many fictional scientists, Meadows is believable: his discourses on turbulence and hydrodynamics are assured, even uncompromising, without the breezy 'beginner's guide' flavour that is the usual hallmark of undigested authorial research. Here Foden had the immense benefit of advice from his father-in-law, Julian Hunt, a leading expert on turbulence and meteorology and, fittingly, a recipient of the Lewis Fry Richardson medal for nonlinear geophysics. Skilfully balancing fact and fiction, Turbulence is dramatic, intelligent and convincing. Philip Ball is a freelance writer. His most recent books form a trilogy called Nature's Patterns.

\section{Bling of the Bactrians}

Afghanistan: Hidden Treasures from the National Museum, Kabul

Metropolitan Museum of Art, New York Until 20 September

Desire for gold has driven people out of their homes and out of their minds. So Soviet archaeologist Viktor Sarianidi cannot have been surprised when a crowd gathered to gawk at a mound he was excavating in northern Afghanistan in 1978. Tillya Tepe, the Hill of Gold, dates to the first century $\mathrm{AD}$, when the land was known as Bactria, and contained the graves of six nomads - a chieftain and five women - buried with more than 20,000 golden and bejewelled belongings, some of which are now on show at the Metropolitan Museum of Art in New York.

Sarianidi sent the treasures to the National Museum in Kabul and returned to Moscow. Then came the wars. The Soviet army invaded Afghanistan in 1979, the National Museum was nearly destroyed by shelling in 1994, and in 2001 it was ransacked by the Taliban. Yet museum guards had hidden the treasures in secret vaults in the presidential palace and kept their location secret for some 25 years.

Afghanistan portrays the tremendous challenges of preserving a country's heritage in the face of war. "All of these artefacts were supposed to have been lost," says curator and archaeologist Fredrik Hiebert, who was invited by the Afghans in 2003 to catalogue the crates when they were rediscovered. "Every time we opened a box, it was like a miracle." Along with the Tillya Tepe gold, the guards had concealed nearly all of the treasures from Kabul's museum.

The exhibition displays artefacts from four archaeological sites, each focusing on a major stage or civilization in Afghanistan's history. They reveal the multiple influences of the Roman, Indian, Greek and Chinese cultures that infiltrated the ancient nation. A second-millennium gold bowl unearthed at the Bronze Age settlement of Tepe Fullol in the northeast of the country is decorated with

bearded bulls, a motif from distant Mesopotamia. The third-century-BC Greek-style city of Aï Khanum, founded after Bactria's conquest by Alexander the Great, yielded two sophisticated sundials: one, carved from limestone in the form of a throne balanced on two lions' legs, was designed for Aï Khanum's latitude; the other, a unique cylindrical design, was calibrated for ancient Syene (Aswan) in Egypt. Another mechanical marvel comes from Begram, a city on the Silk Road that thrived in the first and second centuries AD. A green bronze basin is filled with sinuous metal fish, their moveable fins and tails wired to small weights that would make them 'swim' when the bowl was filled with water.

But the gold of Tillya Tepe is the most alluring. Its pastoralist owners ploughed their profits from sheep- and goat-herding into shimmer-

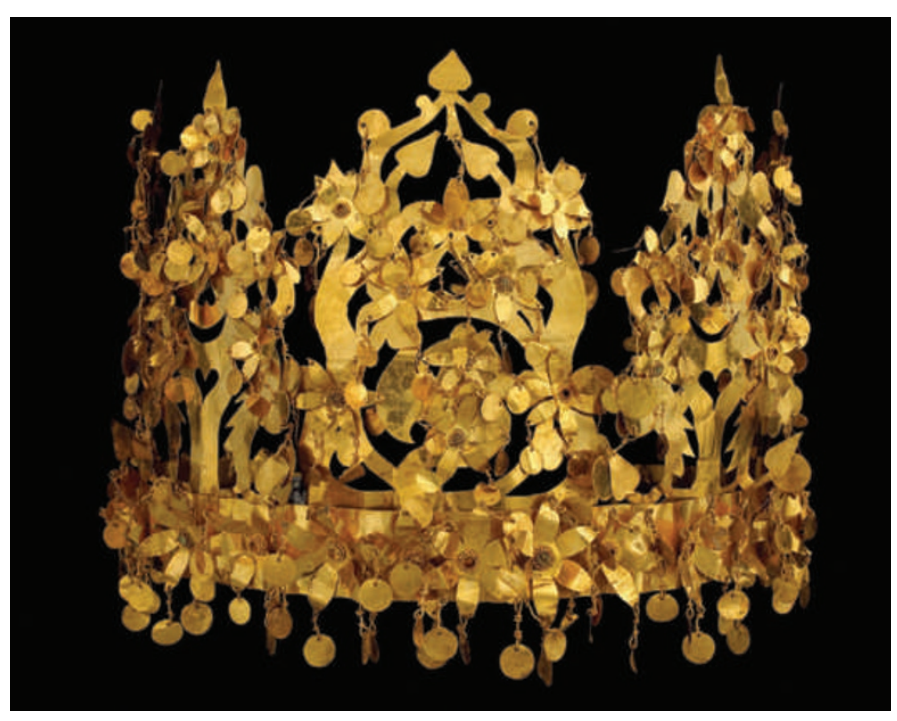

Museum staff hid this folding gold crown from Afghanistan's looters for years. ing trophies ornamented with symbols of diverse cultures: Aphrodite with an Indian dot on her forehead, a dagger handle topped with a Siberian bear, Chinese-style boot buckles, Roman coins, resplendent gold jewellery and a folding gold crown composed of five 'trees' adorned with rosettes and birds. That such valuables survived "is an amazing testament to the Afghans' ability to keep a secret", Hiebert says. "The Communists came through, the mujahedin came through, the Taliban came through, and these poor underpaid museum people didn't tell them, ever. I want to tell that story to my children."

Josie Glausiusz is a writer based in New York.

e-mail:jg@planetjosie.net 